\title{
Reflections on 'Performing' Canadian-ness as a way of 'Passing'
}

\author{
Saba Alvi \\ University of Ottawa \\ salvi@uottawa.ca
}

\begin{abstract}
This reflective essay explores my family's intergenerational experiences of belonging and exclusion in and through Canadian spaces. I share how my parents, first generation Canadians, navigated cultural and religious traditions in order to help their children "pass" as Canadians-meaning, performing "norms" of perceived "Canadian-ness" to fit in. For me, the implications of this resulted in tensions around my identity and self-worth. I unpack personal stories of residing within a "third space," as a second generation Canadian who identifies as and is also visibly identified as, South Asian and Muslim. I close the essay by appealing to Derrida's concept of "unconditional hospitality" as a pedagogical parenting and teaching tool to inform my own children's multifaceted identities as Canadians.
\end{abstract}

\section{Welcome to Canada}

Growing up, my parents shared many stories of how they navigated Canada as new immigrants. My father's story in particular has always fascinated me. Although he has experienced displacement many times, his experiences of exclusion in Canada have had an intergenerational impact on our family's identity. My father lived through the India and Pakistan partition of 1947. He has memories of fleeing his village in India with his family to the newly established Pakistan. He lost his mother at 2 years old. And then his father at 12. With some help from our extended family, he managed to finish his elementary schooling. From thereon in, he got by being academically inclined. He completed the rest of his schooling through various scholarships. To do so, he lived primarily in schooling hostels. He often shared stories of going to bed hungry and borrowing money from friends to buy dinner some nights. In 1970, before leaving Pakistan for Hawaii, my father became a veterinarian. He received a doctoral scholarship to attend the University of Hawaii. Unfortunately, before he could complete his $\mathrm{PhD}$, his scholarship ran out. With no family to support him, he had no choice but to leave the country. Luckily, in 1975, he applied to immigrate to Canada and left Hawaii for Montreal to start all over again with nothing except for some debt. He eventually ended up in Toronto and landed his first job as an office clerk. In 1977, he married my mother. They started their life together in Scarborough, Ontario. It is safe to say that my father is a resilient man who has lived through a war, being an orphan, and now a global pandemic. And yet, the racism and exclusion my father felt in Canada as a new immigrant has informed his experiences, life and actions more than any other event.

\section{Bedtime Stories}

I remember my father telling me a story when I was a young girl about the time our family was almost homeless. It was during the early 1980s in Toronto. My parents had two very young children, a 2-year old son and a newborn daughter. They lived in an apartment building. The 
neighbour who lived below them constantly complained that my siblings were too loud. The harassment led my parents to change apartments. My father gave notice to their landlord and began the hunt for a new place to live. Unbeknownst to him, finding a place to live as a person of colour was extremely hard during this time in Canada. For weeks, my father pursued several vacant ads with no luck. Each time he found an available apartment, made an appointment to give a deposit, he was turned away when he got there and told the apartment had already been rented out. This was always only a few hours after being told to come and sign up for the apartment. My parents' friends and neighbours from immigrant communities of colour started sharing similar stories. My father tried to backtrack and speak to his present landlord to see if our family could stay. But, the landlord refused and said he had already leased out the apartment and my family had to move out by the end of the month. My father became so sick with worry that even his employer noticed and inquired if something was wrong. When my father told him what was happening, he suggested my father complain to the Human Rights Tribunal. The representatives there told him that if even one person of colour was living in the apartment he was declined from, he would not have a case. Finally, a couple of days before his lease was up, my father managed to find an apartment to rent. He still remembers the exact day he found that new apartment to rent and how close my family came to having no place to live. The emotional trauma and stress he suffered has made that experience unforgettable.

Coincidentally, that same month (Summer of 1981), there was a story in the Toronto Sun about the difficult time people of colour were having renting homes in Toronto because of racism. The story, as he recalls, had two men, one white and one black, both well-dressed, soliciting several of the same rent ads. It was no surprise that the white man was offered every single property he pursued while the black man was either turned away or lied to about the price of the rent and told a significantly higher amount then the white man was told.

Throughout the years, my parents have shared many stories of discrimination with us. They were called "pakis" while walking down the street and yelled at to go back home. They were told to learn English even though my father completed most of his education in English. His English was never a problem; I suspect it was his accent. They felt they were overlooked at work and passed up for opportunities for growth and promotion because of the colour of their skin.

While these experiences impacted them emotionally, they also had to seek physical safety for our family on several occasions, like the time they had to move because our house kept getting egged and pummelled with rocks; or the time their apartment became infested with cockroaches, and the landlord refused to help; or the time the air quality in their neighbourhood was so bad it made my dad and brother's asthma unbearable. We moved a lot growing up trying to seek safe spaces to live. Before any move, my mother would always tell us: "Pray we have good neighbours." I now realize that her words were cautionary. What she really meant was: pray our neighbours aren't racist; pray we live in a neighbourhood where we are accepted for who we are. My parents were seeking safety and above all, acceptance as Canadians, as people who belonged. They were seeking "unconditional hospitality" despite the colour of their skin and accent of their voices.

\section{The Real Canadian Experience}

Inevitably, I think my parents' experiences of exclusion and racism informed how they raised us. Reflecting back, I believe they wanted to instill in us a variation of what Bourdieu (1986) referred to as social and cultural capital, that is, the skills and resources we would need to thrive in

Cultural and Pedagogical Inquiry, Fall 2020, 12(2), pp. 18-22

ISSN 1916-3460 () 2020 University of Alberta

http://ejournals.library.ualberta.ca/index.php/cpi/index 
Canada and be accepted across different private and public spaces, regardless of the colour of our skin. Acquiring these capitals, my parents believed, would be possible if we participated in what they interpreted as "Canadian" activities and by doing so, we would hopefully "pass" as Canadian. I went to public schools, sang in the choir, played school sports, took swimming and gymnastics lessons and went to school dances. During Christmas time, we put lights up outside our home and even had a little Christmas tree to decorate and put presents under. They took us tobogganing and ice-skating in the winters and camping and fishing in the summers. My parents gave us the real "Canadian" experience. I put quotations around Canadian because of course there should be no one way to be "Canadian." However, there are clear narratives of how one can perform or prove their Canadian-ness, even though these narratives may simply be myths or guided by a colonial lens.

This is not to say, though, that my parents did not work hard to nourish our identity as Muslims and Pakistanis too. There were rules that were rooted in both culture and religious beliefs: no dating, no revealing clothing and no sleepovers. Sometimes the rules were inconsistent. Sometimes they were confusing. Sometimes we broke the rules.

As a family, we did things that were true to our version of religious and cultural roots. We attended Urdu school on Saturdays and learned Quran at Sunday school. We spoke mostly in Urdu at home and dressed in traditional Pakistani clothing for social gatherings in the community. We ate South Asian foods and visited Pakistan frequently. We fasted during Ramadan and went to the Mosque for events. I did not see these things as being "Canadian." These parts of my identity seemed ancestral and parts of me that were attached to another place. These parts of my identity never felt like they belonged in Canada nor that they were welcomed.

The dual part of my identity has been an ongoing site of tension and negotiation for me. The Canadian part and the other(ed) parts have had a hard time mixing. In fact, for a long time, I did not think the two sides could co-exist. The person I was, at the predominantly white schools I attended growing up, never crossed paths with the person I was at home or within spaces deemed Muslim or South Asian. This complexity only increased as I grew older and became more and more conscious of how I wanted to be perceived. More than anything, I wanted to be accepted and to fit in at school. What kid doesn't want that? Based on my parents' experiences, I did not think it was possible to fit in, or be accepted, if my peers knew who I was outside of school. I went to great lengths sometimes to hide parts of my identity from my school friends. If my family was going to the Mosque and I was wearing traditional clothing, I would make sure no one I knew was passing by in front of my house before I sprinted to the car. I pretended not to know Urdu when my friends asked if I spoke a second language. I learned to stop bringing home-cooked leftovers for lunch because I had heard people make jokes about our food being "stinky." My mother was not even allowed to cook if I had plans to go out with my friends so that my clothes would not reveal any hint of her (our) traditional foods. I went to the deepest corners of my school's hallways and hid under staircases when I wanted to perform obligatory prayers. If there was a chance I would be discovered, I would skip my prayers altogether.

\section{Fitting In}

Fitting in was still hard. At school, people made fun of my name, my food, the hair on my arms and my parents' accents. I tried harder. I dressed like everyone, I bought the same brand of clothing as everyone, I wore what was in "style" and consumed the same music as everyone. A particularly traumatizing experience revolved around Eid, a religious Muslim holiday. Putting

Cultural and Pedagogical Inquiry, Fall 2020, 12(2), pp. 18-22

ISSN 1916-3460 @ 2020 University of Alberta

http://ejournals.library.ualberta.ca/index.php/cpi/index 
henna on my hands was a highlight for me during this time. Applying the intricate designs and waiting for the deep maroon colour to stain my hand was my favourite part as a young girl. It did not take long for the trolls to chime in though: "Don't you wash your hands Saba?" "You look like you have shit on your hands, Saba." I remember going home and scrubbing my hands vigorously to try and get the stain off. I would wrap my hands in bandages and pretend I got hurt in an effort to hide my henna. I even used bleach a couple of times hoping it would help. Eventually, I just stopped putting henna on.

A few years later, Madonna released her single Frozen, and in the opening scenes of the video she is wearing henna on her hands. Overnight, everyone knew what henna was and now it was ridiculously cool. Now that it had been appropriated. Now that it was on white hands. I figured it was safe for me to put henna on again without being made fun of. It was insulting though when I would put it on people would say "Cool, Madonna does that."

Another experience that has stayed with me is an incident that occurred with one of my high school teachers. He refused to accommodate my request to order a vegetarian pizza as part of a class pizza party. "Not my fault your religion doesn't allow pork," he said. "That's your decision not to eat it." His words still sting. I brought my own lunch for the party. I did not know how to advocate for myself then or I would have brought it up with the administration. Sometimes I wonder how supportive the all-white administration would have been. Being part of the very small percentage of minorities in my schools made it hard to take a stand because the lack of support was often apparent. These experiences were confirmation though, that revealing certain parts of my identity made me an outsider in the eyes of many, including my teachers.

I think many minoritized bodies share the same experience as me. We belong to the third, liminal, in-between space that Bhabha (2007) refers to in his work. I feel like I am not seen as belonging "here" but also, I do not fully belong "there" either; "there" being the spaces where I am in the majority as a brown body. While I "fit in" physically and aesthetically in brown spaces, I am perceived at times as "whitewashed." According to some, I dress "white," I speak "white," and I do "white people" things. Some accuse me of also having a "white" profession. I suppose the last accusation is not far from the truth as academia is predominantly a white-employed profession and I am one of very few minoritized bodies in my faculty.

I also acknowledge that over the years as a result of my upbringing and the strategies I have learned, that I know how to "pass" in white spaces. I am able to speak, socialize and write in ways that have allowed me to move around in spaces dominated by white-presenting people. This is the social capital my parents wanted their children to learn. My profession and education also allow me to move around (somewhat) safely in society. This is the cultural capital my parents had hoped for. I still do not feel like I fit in nor that I am accepted fully within these spaces. I perceive that my presence as a Muslim woman who wears hijab is largely overlooked and often stereotyped. My reflex at times, still, is to hide many parts of my Muslim and South Asian identity in order to fit in.

\section{Unconditional Hospitality as a Pedagogical Parenting Strategy}

Recently, I asked my father to write a biography of his life which has undoubtedly been extraordinary. Though, I suspect he does not fully realize it. I asked him to include his memories of his parents, his experiences growing up without any support and how he survived as a new immigrant in Canada. One of the most haunting passages for me from that memoir is my father, now in his late 70s, sharing that he can still vividly remember the feelings of uncertainty he had

Cultural and Pedagogical Inquiry, Fall 2020, 12(2), pp. 18-22

ISSN 1916-3460 () 2020 University of Alberta

http://ejournals.library.ualberta.ca/index.php/cpi/index 
when he did not have much money. How he can still invoke the feelings of terror he felt when he did not know how he would provide for his young family. Not only does he still remember those feelings, memories of those feelings still cause him emotional and psychological discomfort. That discomfort has guided him, at times, to teach his children to play it safe when making choices in life and to do our best to fit in. My parents' experiences of exclusion as immigrants in Canada have had an emotionally traumatic impact on our family that I am actively trying to undo through my parenting and community advocacy.

I have seldom shared my stories of discrimination with my parents. Partially, because I feel it would hurt them to know that despite all their efforts and sacrifices, their children still felt, indeed feel, the demeaning experiences of racism. I also wonder if being discriminated against is a "rite of passage" as a brown or black body in Canada; an inevitable part of being non-white. I heard my parents' stories growing up and now I have my own to share with my children in order to teach them. Warn them.

My children have added layers of complexity though; they are Canadian, they are Muslim, they have Pakistani roots like me and Guyanese roots like their father. They have a rich identity in the making; however, some things are different. The sacrifices my parents made as new immigrants have afforded me many privileges, mainly access to an education that has given me the opportunity to unpack and self-reflect on my family's history and led me to deeply become interested in and committed to anti-racist teachings. I teach my children about being unapologetic about every aspect of their identity. They are allowed to be many things at one time and that is what being Canadian should mean. They do not need to perform their identity in order to prove they belong. They belong. I teach them about advocacy and what that looks like in terms of standing up for themselves and those around them. I am teaching them to normalize the parts of them that others may not be familiar with, like pronouncing their names proudly and eating our traditional Pakistani and Guyanese foods without feeling embarrassed.

They are young, but they know about colonialism and racism, and how that will impact them. The dialogue is simple, but they have a beginning understanding of Turtle Island, Indigenous peoples and the Black Lives Matter movement. We have talked about the difference between welcoming people and tolerating people. Welcoming is what we strive for because it is a good feeling we can give others through our actions. I believe welcoming is what aligns with Derrida's concept of unconditional hospitality and that by introducing discourses around welcoming, especially in child and youth-centred spaces, we as Canadians can begin to move towards Derrida's call. Unconditional hospitality is the pedagogy that drives my parenting. It is the culminating result of a turbulent journey of self-reflection that spans three generations of yearning to belong and "fit in."

\section{Works Cited}

Bourdieu, P. (1986). The Forms of Capital. In J. G. Richardson (Ed.), Handbook of Theory and Research for the Sociology of Education (pp. 241-258). New York: Greenwood Press.

Derrida, J., \& Dufourmantelle, A. (2000). Of hospitality. Cultural memory of the present. Stanford, Calif.: Stanford University Press.

Bhabha, H. K. (2007). The Location of Culture. New York, Routledge Classics.

Cultural and Pedagogical Inquiry, Fall 2020, 12(2), pp. 18-22

ISSN 1916-3460 () 2020 University of Alberta

http://ejournals.library.ualberta.ca/index.php/cpi/index 